\title{
Thoracic cage deformities in the early diagnosis of the Marfan syndrome and cardiovascular disease
}

\author{
TIMOTHY P. OBARSKI, DO \\ WILLIAM A. SCHIAVONE, DO
}

The Marfan syndrome is frequently complicated by cardiovascular abnormalities. Of these, aortic dissection and aortic valve regurgitation are the most lifethreatening. The most noticeable abnormalities of the Marfan syndrome-the skeletal abnormalities - may be subtle and limited. Presented here are five reports of cases of the Marfan syndrome. All patients had potentially lethal cardiovascular complications. Either the syndrome had not been previously diagnosed or the patient had not been adequately monitored despite the the presence of thoracic cage deformities present from youth. The purpose of this report is to heighten recognition of the association of thoracic cage deformities with the Marfan syndrome to permit early diagnosis of the associated cardiovascular complications. Surgical management of these complications can favorably alter the natural history of the Marfan syndrome.

The Marfan syndrome is a hereditary disorder of the connective tissue ${ }^{1}$ first described in

From the Department of Cardiology, Cleveland Clinic Foundation, Cleveland, Ohio. Dr Obarski is a fellow in cardiology. Dr Schiavone is a staff cardiologist in Akron, Ohio and an assistant professor of medicine at the Northeastern Ohio Universities College of Medicine, Rootstown.

Reprint requests to Timothy P. Obarski, DO, Department of Cardiology, Riverside Methodist Hospital, 3535 Olentangy River Rd, Columbus, OH 43214.

$1896 .^{2}$ The genetic pattern is one of autosomal dominant trait with incomplete penetrance, making the phenotypic presentation variable. The prevalence of this disorder is estimated to be 4 to 6 persons per $100,000,{ }^{3}$ with no racial or ethnic predisposition. Diagnostic criteria for the Marfan syndrome are broad and each criterion has degrees of abnormality; therefore, if only the more severe cases are included in this estimate, the estimate may be too low.

The diagnosis of the Marfan syndrome is based on the presence of two or more characteristic familial, ocular, cardiovascular, or skeletal features. The skeletal abnormalities of dolichostenomelia (increased limb length), increased joint laxity, increased floor-to-pelvis measurement, and arachnodactyly are easily recognized signs of the Marfan syndrome. Pectus excavatum, pectus carinatum, and thoracic scoliosis may also be present. These manifestations may occur early in life and can be clues to early diagnosis. The case reports of five patients with the Marfan syndrome are presented here. All had thoracic cage abnormalities present from youth, and all eluded diagnosis or careful monitoring until cardiovascular complications arose. The cases are presented to heighten recognition of the association of thoracic abnormalities with the Marfan syndrome.

\section{Report of cases} Case 1

A 36-year-old woman saw her primary physician and complained of shortness of breath and cough- 

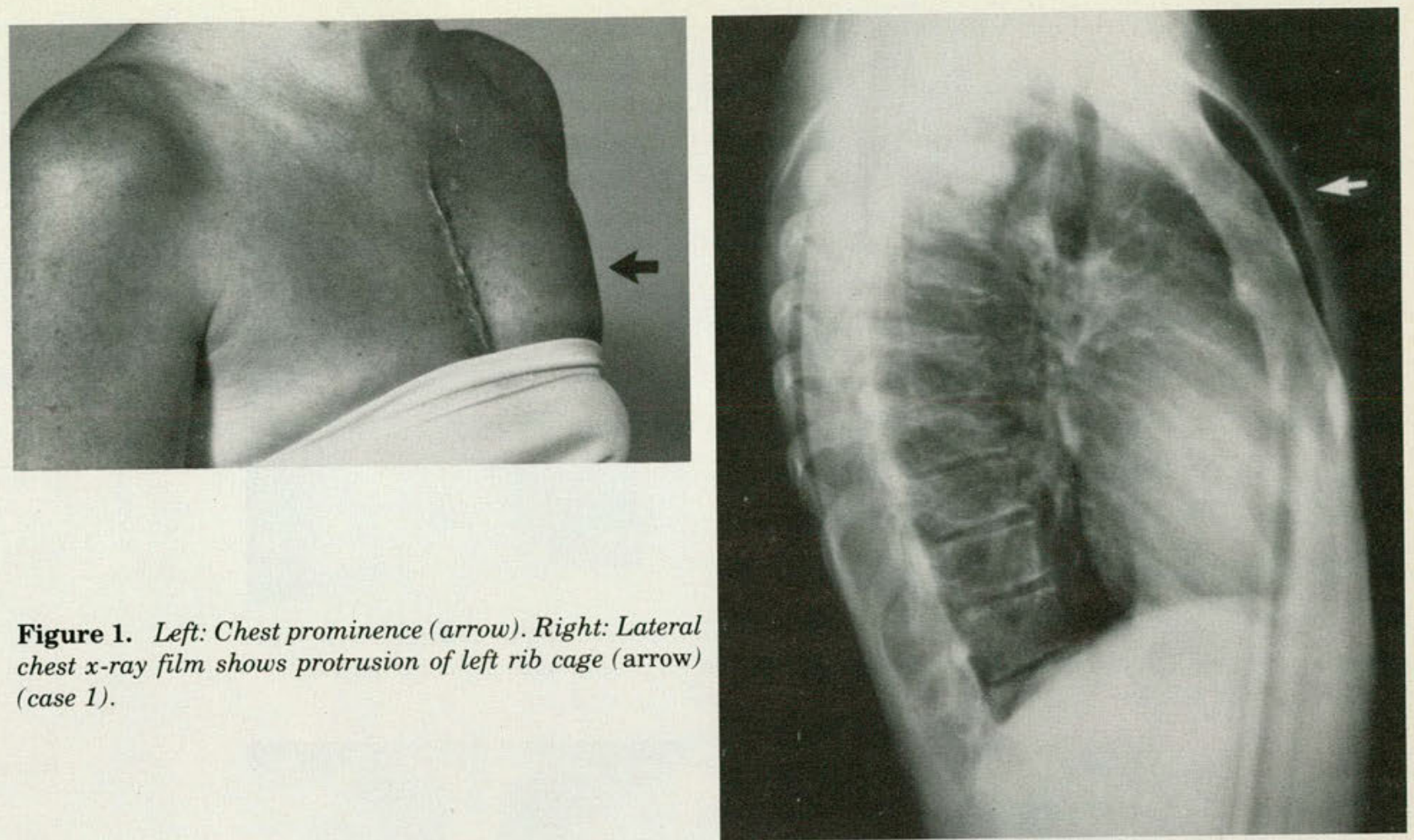

Figure 1. Left: Chest prominence (arrow). Right: Lateral chest $x$-ray film shows protrusion of left rib cage (arrow) (case 1).

ing. She was known to have had a cardiac murmur for 11 years. When antibiotic therapy failed to relieve her symptoms, she was referred to the Cleveland Clinic. Examination revealed pistol-shot pulses, a vibrating systolic murmur, and a diastolic murmur of aortic valve regurgitation. Also noted was a left parasternal chest prominence (Fig 1). A chest x-ray film and an echocardiogram revealed a markedly dilated aortic root. The patient underwent successful repair of the ascending aorta with an aortic-valved conduit with reimplantation of the coronary arteries.

\section{Case 2}

A 39-year-old man with a diagnosis of the Marfan syndrome had had a cardiac murmur since birth. The patient had not received regular medical care. At age 29, acute aortic valve regurgitation developed and required aortic valve replacement. Ten years later, he presented at our clinic with symptoms of congestive heart failure. He was tall and thin with a markedly straightened dorsal spine signifying loss of the normal dorsal kyphosis (Fig 2). A murmur consistent with aortic valve regurgitation was noted. A chest x-ray film revealed marked thoracic lordosis, cardiomegaly, and a normalappearing aorta. An echocardiogram showed aortic root dilation and aortic valve regurgitation. The patient successfully underwent surgical placement of an aortic-valved conduit with reimplantation of the left coronary artery. Reimplantation of the right coronary artery was not surgically possible.

\section{Case 3}

A 26-year-old woman had a strong family history of the Marfan syndrome. Nevertheless, the condition was not so diagnosed until she had an acute aortic dissection. She was found to have a systolic ejection murmur, multiple systolic clicks, joint laxity, arachnodactyly, and a prominent pectus carinatum (Fig 3). Echocardiograms revealed a dilated aortic root and an aortic dissection distal to the left subclavian artery. The patient underwent successful surgical repair of the aneurysm and dissection.

\section{Case 4}

A 32-year-old man had the Marfan syndrome diagnosed at age 12 . The diagnosis was based on skeletal and ocular abnormalities. There was no family history of the disorder. The patient was clinically well until age 32 when he was seen at the Cleveland Clinic with aortic valve endocarditis and aortic valve regurgitation. An echocardiogram revealed an aortic root measuring $5.8 \mathrm{~cm}$ in diameter. The patient had a murmur characteristic of 

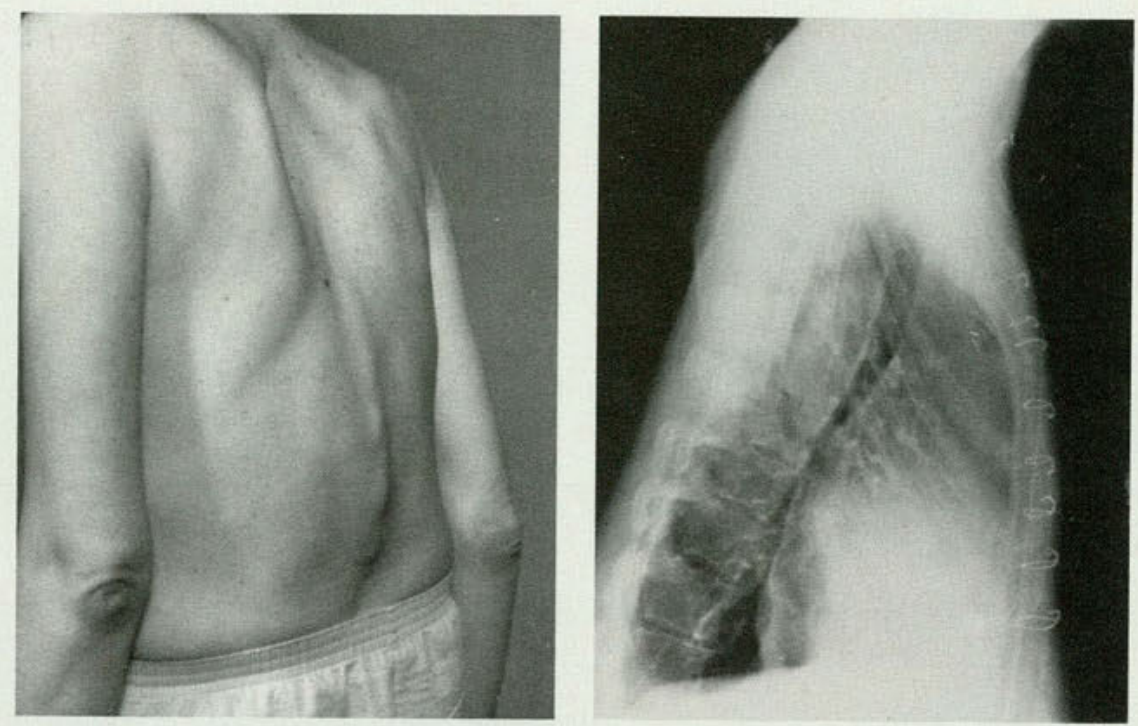

Figure 2. Left: Loss of normal dorsal kyphosis. Right: Lateral chest $x$-ray film shows marked dorsal lordosis and relative lumbar kyphosis (case 2).
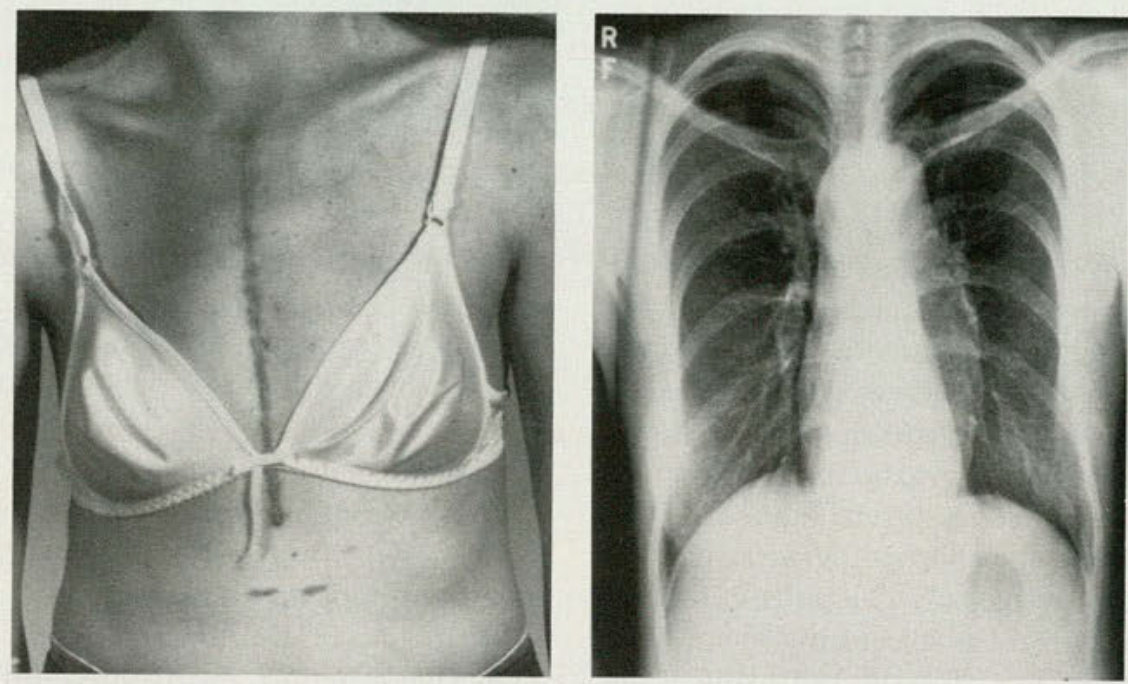

Figure 3. Left: Prominent pectus carinatum. Right: Posteroanterior chest $x$-ray film shows widening of the ascending and descending aortas consistent with ascending aortic aneurysm and descending aortic dissection (case 3).

aortic valve regurgitation, pectus excavatum (Fig 4), ectopia lentis, and a high arched palate. There were no arachnodactyly or dolichostenomelia. $\mathrm{He}$ underwent successful surgical repair with aorticvalved conduit with reimplantation of the coronary arteries.

\section{Case 5}

A 37-year-old woman with intermittent, sharp chest pain was seen at the Cleveland Clinic. She had been told as a child that she had a cardiac murmur but there had been no further investigation.
The patient had had three first-trimester spontaneous abortions and chondromalacia patellae. She denied chest trauma but was concerned about the pain because her father had had surgery for a thoracic aortic aneurysm. The findings of the cardiac examination were normal; however, skeletal examination revealed dolichostenomelia, arachnodactyly, torus palatinus, and pectus excavatum. She had seen numerous physicians but had never had her condition diagnosed as the Marfan syndrome. Despite a chest x-ray film that revealed a normalappearing heart and aorta, an echocardiogram 


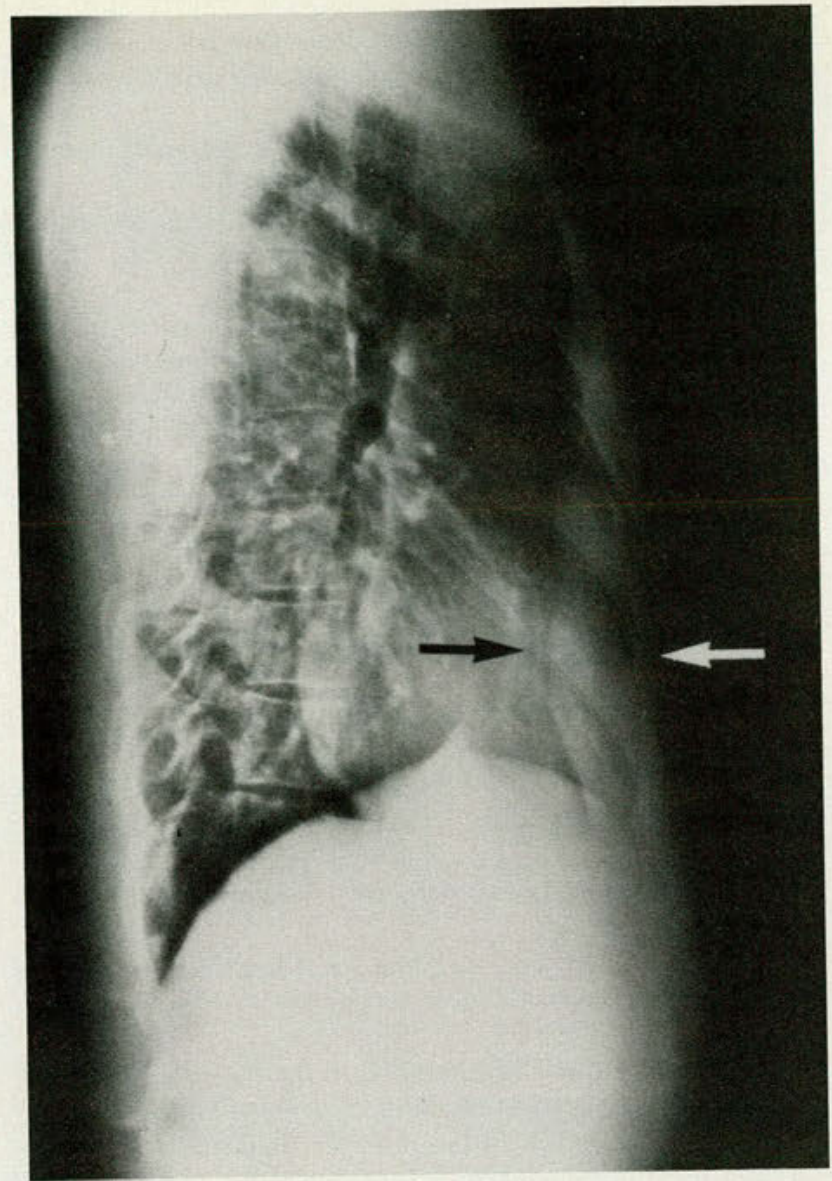

Figure 4. Lateral chest $x$-ray film shows sternal depression (arrows) consistent with pectus excavatum (case 4).

showed a dilated ascending aorta (Fig 5) at the level of the sinuses of Valsalva. The patient now undergoes a yearly echocardiogram to assess the aortic root size.

\section{Discussion}

Thoracic cage abnormalities can be an early clue to the diagnosis of the Marfan syndrome. Classic skeletal signs include dolichostenomelia, arachnodactyly, and increased floor-topelvis measurement. Pectus carinatum, including unilateral pectus carinatum, pectus excavatum, loss of the normal dorsal kyphotic curve, and scoliosis, can also indicate this syndrome. A high index of suspicion of the Marfan syndrome in patients with skeletal abnormalities can lead to early detection of its cardiovascular complications. These complications are responsible for more than $95 \%$ of the discernible causes of death in patients with the

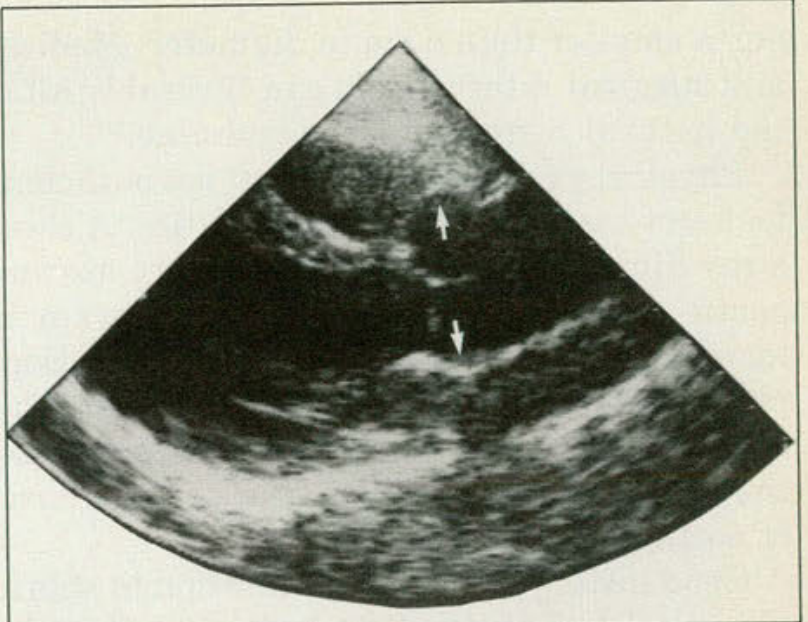

Figure 5. Two-dimensional echocardiogram. Anterior and posterior walls of the aortic root (arrows) dilated to $4.1 \mathrm{~cm}$ at level of sinuses of Valsalva (case 5).

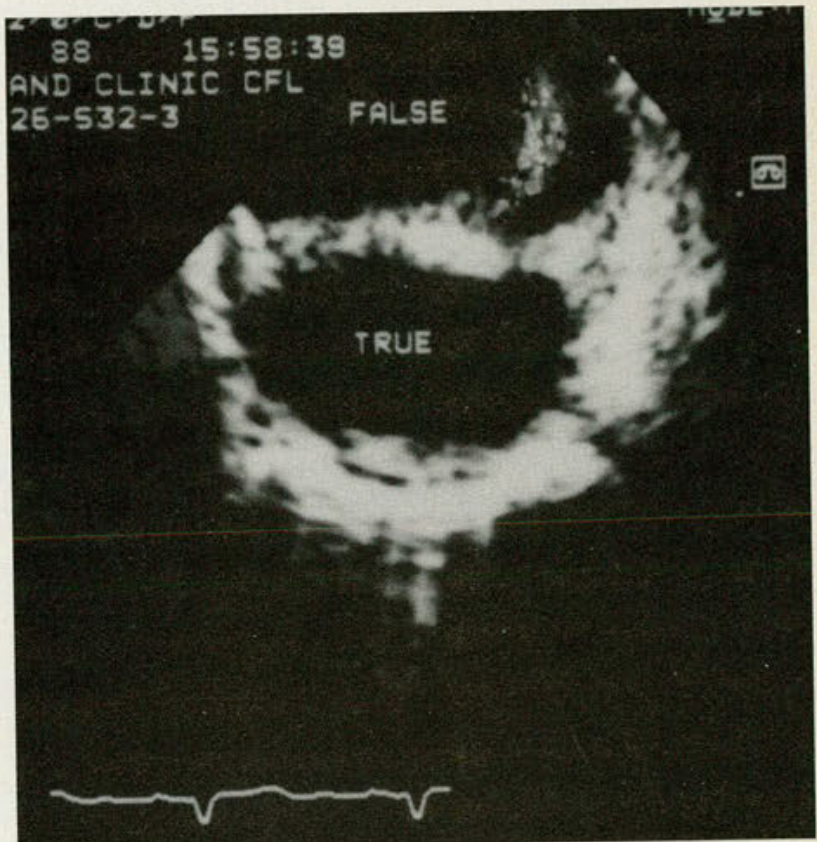

Figure 6. Transesophageal echocardiogram. Note true and false lumens of this aortic dissection. Blood flows from true to false lumen.

Marfan syndrome and are the primary reason that these patients' life expectancy is halved. ${ }^{4}$

Cardiovascular abnormalities in patients with the Marfan syndrome are many,,$^{3,5-9}$ but the most life-threatening-and the cause of death in $29 \%$ to $43 \%$ of these patients ${ }^{10,11}$-is dissection of the ascending aorta. Dilation of the aorta or annulo-aortic ectasia ${ }^{12}$ progresses gradually over years, but dissection with aortic valve regurgitation seldom occurs with an 
aorta smaller than $6 \mathrm{~cm}$ in diameter. Medical and surgical intervention can favorably alter the natural history of this syndrome. ${ }^{13}$

Physical examination is often not sufficient to detect cardiovascular abnormalities. A chest $\mathrm{x}$-ray film is helpful in assessing heart size and aortic diameter, but an echocardiogram is more precise. ${ }^{6}$ The addition of color flow Doppler and transesophageal echocardiography (Fig 6) to conventional echocardiography further improves the specificity for the diagnosis of aortic dissection. ${ }^{14}$

Good history taking and attention to subtle abnormalities of the chest wall can aid in the prospective diagnosis of the Marfan syndrome and its cardiovascular complications, providing the opportunity for elective surgical repair. Such repair can be performed successfully in nine out of ten cases, ${ }^{15}$ clearly a favorable alteration in the natural history of the syndrome. ${ }^{4,13}$

The authors wish to thank Philip Currie, MBBS, for his contribution to this paper.

1. McKusick VA: Cardiovascular aspects of the Marfan syndrome: Heritage disorder of connective tissue. Circulation 1955;11:321-324.

2. Marfan AB: Un cas de déformation congénitale des quartre membres, plus prononcée aux extremités, caractérisée par Ial- longement des os avec un certain degré damincissement. Bulletin de la Société Médicale des Hopitaux de Paris 1896;13:220. 227.

3. Pyeritz RE, McKusick VA: The Marfan syndrome: Diagnosis and management. N Engl J Med 1979;300:772-777.

4. Murdoch JL, Walker BA, Halpren BL, et al: Life expectancy and causes of death in the Marfan syndrome. $N$ Engl $J$ Med 1972;286:804-808.

5. Salle V: Uebereinen fall von angeborener abnormei Grosse du Extermitaten mit einem an akromegalie erinnernden symptomen komplex. Jahrb Kinderheilkd 1912;75:540-550.

6. Come PC, Fortuin NJ, White RI Jr, et al: Echocardiographic assessment of cardiovascular abnormalities in the Marfan syndrome: Comparison with clinical findings and roentgenographic estimation of aortic root size. Ann Med 1983;74:465-474.

7. Eldridge R: Coarctation in the Marfan syndrome. Arch Intern Med 1964;113:342-349.

8. Lillian M: Multiple pulmonary artery aneurysms. Am J Med 1947;7:280-287.

9. Anderson M, Pratt-Thomas HR: Marfan's syndrome. Am Heart $J$ 1951;46:814-825.

10. Marvel RS, Genovese PD: Cardiovascular disease in Marfan's syndrome. Am Heart $J$ 1951;42:814-825.

11. Thomas J, Brothers GB, Anderson RS, et al: Marfan's syndrome: A report of 3 cases with aneurysm of the aorta. Am J Med 1952;12:613-618.

12. Ellis PR, Cooley DA, Debakey ME: Clinical considerations and surgical therapy of annulo-aortic ectasia. J Thorac Cardiovas Surg 1961;42:363-369.

13. Cooke JP, Safford RE: Progress in the diagnosis and management of aortic dissection. Mayo Clin Proc 1986;61:147-153.

14. Borner N, Erbel R, Braun B, et al: Diagnosis of aortic dissection by transesophageal echocardiography. Am $J$ Cardiol 1984;54:1157-1158.

15. Davis Z, Pluth JR, Giuliani ER: The Marfan syndrome and cardiac surgery. J Thorac Cardiovas Surg 1978;75:505-509. 